\title{
Enhanced Bioavailability of Fenoterol Transdermal Systems in Rabbits
}

\author{
A.H. Elshafeey ${ }^{1,2 *}$, Y.E. Hamza ${ }^{2}$, S.Y. Amin² ${ }^{2}$ F. Akhlaghi' ${ }^{1}$ and H. Zia ${ }^{1}$ \\ ${ }^{1}$ Applied Pharmaceutical Sciences, College of Pharmacy, University of Rhode Island, Kingston, RI, 02881, USA \\ ${ }^{2}$ Pharmaceutics Department, Faculty of Pharmacy, Cairo University, Egypt
}

\begin{abstract}
The pharmacokinetic and bioavailability of fenoterol, a $\mathrm{B}_{2}$ adrenergic agonist were studied to determine the feasibility of enhanced transdermal delivery. Fenoterol has been widely used to treat asthmatic patients. Two fenoterol formulations were studied; the first was a liquid formulation of fenoterol in Transcutol: Oleic acid in a ratio 1:1(F1), while the second was a matrix system of fenoterol in Duro-tak ${ }^{\circledR} 87-2074$ adhesive with $10 \% 1$-dodecyl-2pyrrolidinone as an enhancer (F2). For comparison, control matrix with fenoterol without any enhancer (F3) was also tested. The tested formulations were applied to the shaved back skin of rabbits using HILL TOP CHAMBER ${ }^{\circledR}$ in case of liquid formula. Blood samples were collected via auricle central vein for 24 hours and the plasma concentrations of fenoterol were determined by LC-MS/MS method. Pharmacokinetic parameters were calculated using the WinNonlin computer program.

The results showed a maximum concentration of fenoterol in plasma of $514.8 \mathrm{ng} / \mathrm{ml}$ after application of the liquid formula while its AUC amounted to be $485972\left(\mathrm{ng}^{*} \mathrm{~min} / \mathrm{ml}\right)$ with a dose of $3 \mathrm{mg} / \mathrm{kg}$. The transdermal matrix prepared with $10 \%$ 1-dodecyl-2-pyrollidinone had a $C_{\max }$ of $219 \mathrm{ng} / \mathrm{ml}$ and $A_{U C} C_{0-\infty}$ was $124636\left(\mathrm{ng}^{*} \mathrm{~min} / \mathrm{ml}\right)$ which is significantly higher than that obtained after application of the control patch without any enhancer. Therefore, the transdermal systems will offer an efficient drug delivery system for the treatment of bronchial asthma.
\end{abstract}

Keywords: Fenoterol; Transdermal; Rabbits; Enhancers; Mass spectroscopy; Pharmacokinetics

\section{Introduction}

Fenoterol is a $\mathrm{B}_{2}$ adrenergic agonist, which is effective bronchodilator in animals and human when given by inhalation or by oral route [1] . Following the administration of several $\mathrm{B}_{2}$ stimulants oral or inhaled, fenoterol is superior to isoprenaline, orciprenaline and salbutamol in protecting against bronchospasm and is longer acting.

Fenoterol is rapidly absorbed following oral ingestion or inhalation. Its oral bioavailability is low, only $2 \%$. It is rapidly metabolized to sulphate and glucuronide conjugates [2]. Following oral doses of tritiated fenoterol, peak plasma levels of radioactivity were attained in about 2 hours and were mainly due to metabolites rather than fenoterol itself. Approximately $60 \%$ of an oral dose is absorbed. There have been few reports of side effects following inhalation of usual therapeutic doses of fenoterol. Tachycardia, nervousness and palpitations have been reported [1]. Therefore, the development of transdermal controlled drug delivery system of fenoterol without adverse effects which could occur when administered orally is very important.

In a previous work [3], the fenoterol liquid formula in oleic acid and transcutol and fenoterol matrix transdermal patches containing 1-dodecyl-2-pyrolidinone as an enhancer were formulated and in vitro tested using hairless guinea pig skin. The objective of this study was to determine the feasibility of transdermal delivery of fenoterol by studying its in vivo absorption characteristics and to develop the fenoterol matrix system containing a penetration enhancer.

\section{Materials and Methods}

\section{Materials}

Fenoterol (CAS 1944-12-3) lot \# 41 K1744, oleic acid, Albuterol sulfate were purchased from Sigma (St.Louis, Mo, USA), HPLC grade acetonitrile and methanol (Fisher Scientific, N.J, USA), Transcutol ${ }^{\circledR}$ (Gattefossẻ, St.Priest, France), 1-dodecyl-2-pyrrolidinone (DPY) was purchased from Aldrich chemical company (Milwakee, W.I, USA).
Duro-Tak ${ }^{\circledR}$ 87-2074 was purchased from National Starch \&Chemical Company (N.J, USA). Scotchpak ${ }^{\circledR}$ polyester multi lam film 10062.84 $\mathrm{mm}$ and Scotchpak ${ }^{\circledR} 1022$ release liner $3 \mathrm{~mm}$ from (3M,St.Paul, MN, USA), HILL TOP CHAMBER ${ }^{\circledR}$ (Hill Top Research, Miamiville, Ohio, USA). All other reagents were of analytical grade.

\section{Animal model}

Five white Newzeland female rabbits weighing 3.6-4.5 Kg were purchased from Harlan labs (Indianapolis, In., USA). The study protocol was reviewed and approved by the Institutional Animal care and use Committee IACUC (University of Rhode Island, Kingston, RI, USA).

\section{Preparation of the tested formulae}

Fenoterol liquid formula (F1) was prepared by dissolving the drug in a mixture of transcutol: oleic acid 1:1 in a concentration of 10 $\mathrm{mg} / \mathrm{ml}$. this system was previously chosen as the best effective liquid formulation [3].

Prototype patch (F2) was prepared using a lab hand coater. Durotak $^{\circledR}$ 87-2074 pressure sensitive adhesive containing $28 \%$ total solids was chosen as the most suitable adhesive. The calculated amount of fenoterol was dispersed in a mixture of adhesive and the selected enhancer in a ratio 9:1. Following drug mixing the drug/adhesive dispersion was coated using a lab-hand coater adjusted at $500 \mu \mathrm{m}$ onto

*Corresponding author: Ahmed Elshafeey, Pharmaceutics Department, Faculty of Pharmacy, Cairo University, Egypt, Tel: +20105840261; E-mail: Ah_elshafeey@ hotmail.com

Received April 04, 2011; Accepted July 06, 2011; Published July 08, 2011

Citation: Elshafeey AH, Hamza YE, Amin SY, Akhlaghi F, Zia H (2011) Enhanced Bioavailability of Fenoterol Transdermal Systems in Rabbits. J Bioequiv Availab 3 : 097-100. doi:10.4172/jbb.1000067

Copyright: ( 2011 Elshafeey $\mathrm{AH}$, et al. This is an open-access article distributed under the terms of the Creative Commons Attribution License, which permits unrestricted use, distribution, and reproduction in any medium, provided the original author and source are credited. 
a scotch pak $^{\circledR} 1022$ release liner $\left(3 \mathrm{M}\right.$, ST.Paul, MN) and cured at $65^{\circ} \mathrm{C}$ for half an hour, then the laminate were covered with a heat seable backing polyester film 1006 (3M, ST.Paul, MN) and kept in the dark at room temperature until use. The patches were prepared using $12 \%$ $(\mathrm{w} / \mathrm{w})$ fenoterol and $10 \%(\mathrm{w} / \mathrm{w})$ of 1-dodecyl-2-pyrolidinone (DPY) as an enhancer.

The control patch (F3) was prepared using $12 \%$ fenoterol without any enhancers.

\section{In vivo percutaneous absorption}

The hair of the back area of each rabbit was carefully removed with an electric clipper 24 hours prior to application of the formulation. The liquid formula in a dose of $3 \mathrm{mg} / \mathrm{kg}$ fenoterol was applied to the rabbit back skin using HILL TOP CHAMBER ${ }^{\circledR}$ plain patch with $1 \mathrm{~cm}$ diameter.

On the other hand, the transdermal therapeutic system of fenoterol in Duro-tak ${ }^{\circledR}$ adhesive with 10\% 1-dodecyl-2-pyrolidinone (F2) and control one (F3) were cut into pieces that contain fenoterol in a dose of $3 \mathrm{mg} / \mathrm{kg}$ were applied to the shaved back rabbit skin.

Blood samples were withdrawn from the central ear vein at $0.5,1$, $1.5,2,3,4,6,8,10,12,18$, and 24 hours after dosing. The blood samples were collected in $2 \mathrm{ml}$ vaccutainer collecting tubes containing EDTA and then centrifuged at $3000 \mathrm{rpm}$ for 12 minutes. The supernatant was transferred into another tubes, sealed and stored at $-20^{\circ} \mathrm{C}$ until assayed. The homeostasis of the rabbits was maintained by injection of same volume of physiological saline via the fixed catheter in the central auricle vein.

\section{Sample preparations}

Aliquots of $800 \mu \mathrm{l}$ rabbit blank plasma for calibration or rabbit samples equilibrated at room temperature and then added to $7 \mathrm{ml}$ glass centrifuge tube with ground glass stopper. The aliquots were spiked with $200 \mu \mathrm{l}$ salbutamol sulfate as internal standard containing $80 \mathrm{ng}$ and then mixed with $2 \mathrm{ml}$ acetonitrile on a reciprocating shaker for 10 $\min [4]$.

After centrifugation at $4000 \mathrm{rpm}$ for 5 minutes, the supernatant was transferred to a second series of glass tube. The solvent was removed in a spd 1010 speedVac system (Savant Instruments, Farmingdale, NY, USA) at $75^{\circ} \mathrm{C}$ for two hours. The residue was then reconstituted in $1 \mathrm{ml}$ phosphate buffer $(0.1 \mathrm{M}, \mathrm{pH}$ 6) and as above extracted for 10 min. into $2 \mathrm{ml}$ 2-butanol. After centrifugation (5 min., $4000 \mathrm{rpm}$ ) the supernatant was transferred into another series of tubes and again dried in speedVac at $75^{\circ} \mathrm{C}$ for two hours. The residue was dissolved in 1 $\mathrm{ml}$ mobile phase and $50 \mu \mathrm{l}$ was injected in the column using series 200 Perkin-Elmer auto sampler.

\section{Determination of fenoterol in rabbit plasma}

Fenoterol in rabbit plasma was determined using LC-MS/MS method as follow:

\section{HPLC Apparatus and conditions}

The HPLC system consisted of a series 200 binary micro-pump and series 200 auto sampler from Perkin-Elmer (Danbury, CT, USA). The column was symmetry ${ }^{\circledR} \mathrm{C}_{18}$ - reversed phase column $3.5 \mu \mathrm{m}$. $4.6 \mathrm{x}$ $75 \mathrm{~mm}$ (Waters, Milford, MA, USA). The mobile phase consisted of $30 \%$ methanol and $70 \% 5 \mathrm{mM}$ Ammonium acetate buffer (pH 5.5). The system operated at a flow rate $0.5 \mathrm{ml} / \mathrm{min}$. and the volume of injection was $50 \mu$ l.

\section{MS Apparatus and conditions}

Mass spectrometric detection was performed on a Sciex API 2000 triple quadropole mass spectrometer with a turbo-ion spray (heated electrospray) interface from PE Applied Biosystems (PE-Sciex, thorn hill, Toronto, Canada) using MRM (multiple reaction mode).

The ion spray interface was used in positive mode and the turbo ion spray source was heated to $450^{\circ} \mathrm{C}$. To obtain predominantly protonated species of the analyte, an ionization voltage of 4500 Voltefor both fenoterol and salbutamol, an orifice voltage of $35 \mathrm{Volt}$ and 25Volt, a collision energy of 40 volt and 25 volt was adjusted for fenoterol and salbutamol respectively. The first quadropole was set to select the protonated ions of fenoterol $[\mathrm{M}+\mathrm{H}]^{+}(\mathrm{m} / \mathrm{z} 304.1)$ and for salbutamol $[\mathrm{m} / \mathrm{z} 240.2]$. The second quadropole was then used as a collision chamber using high-purity Nitrogen gas as the collision gas at 7 to produce different product ion and the third quadruple was then used to select the characteristic most intense product ion of fenoterol (m/z 106.9) and (m/z 148) for salbutamol.

PE Sciex Analyst (ver.1.2) software was used to control the LC$\mathrm{MS} / \mathrm{MS}$ and to acquire the output signals from the detector. Also the same software was used for integration of peak areas and peak heights, calculation of peak area ratios, calibration curves, and the drug concentration.

\section{Pharmacokinetic data analysis}

A non compartmental model analysis was selected for the pharmacokinetic parameters estimation for the transdermal delivery systems. The area under the curves (AUC) from time zero to infinity, $\mathrm{C}_{\max }, \mathrm{t}_{\max }$, and the elimination rate constant $\left(\mathrm{K}_{\mathrm{el}}\right)$ were estimated using WinNonlin.

A single factor ANOVA test was used to determine if any statistically significant difference existed between formulations followed by Fisher's least significant difference test using statistical software, Stat View version 4.57 (CA,USA)[5].

\section{Results}

The plasma fenoterol concentrations during a single percutaneous application of the three tested formulations are graphically represented in Figure 1. The maximum plasma level ( $\left.c_{\max }\right)$ of the liquid formula $(\mathrm{F} 1)$ showed the highest value among all other transdermal formulae with the value of $514.8 \mathrm{ng} / \mathrm{ml}$ as shown in Table 1 reached in a relatively short time $\left(\mathrm{t}_{\max } 114 \mathrm{~min}\right.$.).

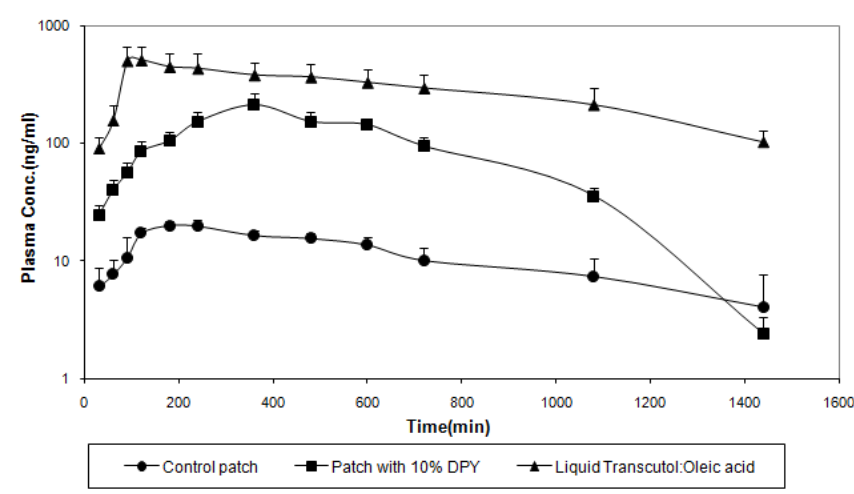

Figure 1: Plasma concentration of fenoterol after single percutaneous administration of fenoterol formulations. 


\begin{tabular}{|c|c|c|c|}
\hline Parameter & Liq.Tc:Oleic & 10\%DPY patch & Control patch \\
\hline $\mathrm{C}_{\max }(\mathrm{ng} / \mathrm{ml})$ & $514.8 \pm 150.83$ & $219.0 \pm 36.5$ & $20.2 \pm 2.0$ \\
\hline$t_{\text {max }}$ (min.) & $114.0 \pm 13.41$ & $408.0 \pm 107.3$ & $204.0 \pm 32.8$ \\
\hline $\mathrm{K}$ el $\left(\min ^{-1}\right)$ & $0.0012 \pm 0.0005$ & $0.0030 \pm 0.0004$ & $0.0010 \pm 0.0005$ \\
\hline$t_{1 / 2 \text { (min.) }}$ & $571.1 \pm 24.8$ & $264.2 \pm 36.1$ & $620.6 \pm 293.5$ \\
\hline AUC ${ }_{\text {inf }}\left(\mathrm{ng}^{*} \min / \mathrm{ml}\right)$ & $485972 \pm 148347$ & $124636 \pm 19811$ & $20715 \pm 9357$ \\
\hline MRT (min.) & $880.3 \pm 18.2$ & $527.9 \pm 30.9$ & $929.1 \pm 442.4$ \\
\hline
\end{tabular}

All formulae between the same brackets are not significantly different from each other but differ significantly from those included in other brackets $(\mathrm{P}<0.001)$ C (ng/ml): (Liq.Tc:Oleic) (10\%DPY patch) (Control Patch)

$\mathrm{AUUC}_{(0-\infty)}\left(\mathrm{ng}^{*} \mathrm{~min} / \mathrm{ml}\right):$ (Liq.Tc:Oleic) $(10 \% \mathrm{DPY}$ patch) (Control Patch)

Table 1: Pharmacokinetic Parameters of Fenoterol after Transdermal Applications.

In a previous work [3], this formula showed the highest permeation flux through hairless genia pig skin over all other tested liquid formulae using different solvents or co-solvents. The area under plasma curve $\left(\mathrm{AUC}_{0-\infty}\right)$ for Transcutol: Oleic acid formula was the highest compared to the other two tested transdermal matrix with a value of 485972 $\left(\mathrm{ng}^{\star} \mathrm{min} / \mathrm{ml}\right)$. This formula achieved a longer elimination half-life value (571.1 minutes) as well as longer MRT (880.33 minutes).

The plasma levels of fenoterol after 24 hours application of a transdermal matrix with 10\% 1-dodecyl-2-2pyrollidinone (DPY) (F2) as a proven efficient enhancer showed a maximum concentration of $219 \pm 36.52 \mathrm{ng} / \mathrm{ml}$ after 408 minutes as shown in Table 1 , which is about 10 times higher than the maximum plasma level of the control transdermal matrix without any enhancer in case of (F3). The area under the curve in presence of $10 \%$ DPY as enhancer was 124636 $\mathrm{ng}{ }^{*} \mathrm{~min} / \mathrm{ml}$ which is about 6 times higher than the plain patch without enhancer. The elimiation half-life was amounted to be 264.2 minutes with a mean residence time (MRT) of 527.9 minutes.

The control patch (F3) showed a $t_{\max }$ of 204 minutes and a elimination half-life of 620.6 minutes with a mean residence time (MRT) of 929.1 minutes. The single factor ANOVA was performed on the $\mathrm{C}_{\max }$ data for the three tested transdermal formulations indicated a statistically difference $(\alpha=0.05), P<0.0001)$ among these formulations.

The Fisher's PLSD test showed that the liquid formulation (Transcutol: Oleic acid) was significantly different from the patch containing $10 \%$ DPY as well as the plain patch. In addition, the $10 \%$ DPY patch differ significantly in the maximum concentration from plain patch without any enhancer. The same results were also obtained in case of the single factor ANOVA performed on the area under the plasma-time curve $\left(\mathrm{AUC}_{0-\infty}\right)$.

\section{Discussion}

The results of this study indicated that the transdermal delivery of fenoterol has considerable potential. In previous study [3], the liquid formula containing transcutol: Oleic acid in 1:1 ratio showed the highest permeation coefficient compared with many other solvents or co-solvents. Also transcutol: Oleic acid showed the least lag time $(0.66$ $\mathrm{hr}$ ) regarding the in vitro permeation through hairless guinea pig skin as well as a high steady state flux $\left(4645.76 \mu \mathrm{g} \cdot \mathrm{cm}^{-2} \cdot \mathrm{hr}^{-1}\right)$.

The increased maximum concentration of fenoterol in plasma as well as the area under the curve might be explained to the limited solubility of fenoterol in oleic acid [6]. Almirall et al. noticed that, increasing the drug solubility in the vehicle will lower its thermodynamic activity in this vehicle and hence decreases the drug permeation through the skin

Oleic acid as a fatty acid is known to have a potent skin permeation enhancing effect when used alone or in combination with glycols (Viz. Transcutol) $[7,8]$. Oleic acid appears to involve the disruption of lipid bilayer that is filling the extra cellular spaces of stratum corneum. It has been postulated to act by increasing the fluidity of skin liquid $[9,10]$ and by forming a fluid phase within the stratum corneum [11]. The shortness of the lag time in the in-vitro permeation previously done [3] is responsible for that Transcutol: Oleic acid formula has a short $t_{\max }$ of $114 \mathrm{~min}$. it is worthy to note that this liquid formula has the longer elimination half-life compared to the enhanced matrix with a strong proof of better sustainability. Transdermal application of fenoterol matrix containing 10\% 1-dodecyl-2-pyrollidinone (DPY) to rabbits showed a relatively constant, sustained blood concentration with minimal fluctuation and better bioavailability with compared control matrix without enhancer. Compared to the liquid formula, the latter superseeds as it has a higher $\mathrm{C}_{\max }$ and $\mathrm{AUC}_{0-\infty}$ with longer $\mathrm{t}_{1 / 2}$.

The enhanced permeation of fenoterol was mainly due to 1-dodecyl-2-pyrollidinone (DPY) which is azone ${ }^{\circledR}$ derivative. It has 5 membered lactam moieties showed greater transdermal enhancement activity compared to 6- and 7- membered (azone) lactam moieties [12] The high enhancer activity of azone ${ }^{\circledR}$ has been postulated to be due to the fact that the cyclic structure possesses a spoon shaped molecular configuration. Interaction with azone ${ }^{\circledR}$ may lead to an unbalanced electronegative site on ceramide matrix thereby, creating a pathway for penetration of drug through the skin [13].

Cyclic azone ${ }^{\circledR}$ such as1-dodecyl-2-pyrollidinone (DPY) may be more effective enhancers based on their electrostatic repulsion and their ability to better dislocate the ceramide matrix [14].

\section{Conclusion}

The results of this study shows that the transdermal delivery of fenoterol either from the liquid formula containing transcutol: Oleic acid in 1:1 ratio or the fenoterol matrix using Duro-Tak ${ }^{\circledR}$ as a pressure sensitive adhesive with 10\% 1-dodecyl-2-pyrollidinone (DPY) as an enhancer could be developed to provide a consistent plasma concentration above the therapeutic level for up to 24 hours.

The application of a transdermal liquid or matrix formulation once a day reduces the dose and frequency of dosing and improves the patient compliance. The most important acheviment is to overcome the extensivee first pass effect of the orally adminstered fenoterol [2]. In a previous work [15], the reached Cmax for orally adminstered fenoterol to beagal dogs was $146 \mathrm{ng} / \mathrm{ml}$ for the immediate release tablets. The higher Cmax for the transdermal delivery systems (514 and $219 \mathrm{ng} /$ $\mathrm{ml}$ for the liquid formula and the enhanced matrix respectively) may account for the better bioavailability and lower first pass metabolism. It may also prevent nocturnal wheezing in case of asthmatic patients.

Transdermal delivery of fenoterol may offer certain advantages over oral, aerosol and parental delivery. Delivery of the drug in a continuous manner would extend the duration of action, pharmacological effect and minimizing the dose and frequency of dosing so that decreasing any associated side effects.

\section{References}

1. Heel RC, Brogden RN, Speight TM, Avery GS (1978) Fenoterol: a review of its pharmacological properties and therapeutic efficacy in asthma. Drugs 15: 3-32.

2. Gleiter CH (1999) Fenoterol: Pharmacology and Clinical Use. Cardiovascular Drug Reviews 17: 87-106.

3. Elshafeey YHA, Amin S, Zia H (2011) In vitro Transdermal Permeation of Fenoterol Hydrobromide, J Adv Res doi:10.1016/j.jare.2011.05.009

4. Meineke I, Steinmetz H, Kramer S, Gleiter $\mathrm{CH}$ (2002) Determination of fenotero in human plasma by HPLC with fluorescence detection after derivatization. J Pharm Biomed Anal 29: 147-152. 
Citation: Elshafeey AH, Hamza YE, Amin SY, Akhlaghi F, Zia H (2011) Enhanced Bioavailability of Fenoterol Transdermal Systems in Rabbits. J Bioequiv Availab 3: 097-100. doi:10.4172/jbb.1000067

5. Mongamery DC (1991) ed. Design and Analysis of Experiments. John Wiley: New York.

6. Almirall M, Montana J, Escribano E, Obach R, Berrozpe JD (1996) Effect of d-limonene, alpha-pinene and cineole on in vitro transdermal human skin penetration of chlorpromazine and haloperidol. Arzneimittelforschung 46: 676680 .

7. Cooper ER (1984) Increased skin permeability for lipophilic molecules. J Pharm Sci 73: 1153-1156.

8. Williams AC, Barry BW (1992) Skin absorption enhancers. Crit Rev Ther Drug Carrier Syst 9: 305-353.

9. Barry BW, Fyrand O, Woodford R, Ulshagen K, Hogstad G (1987) Control of the bioavailability of a topical steroid; comparison of desonide creams $0.05 \%$ and $0.1 \%$ by vasoconstrictor studies and clinical trials. Clin Exp Dermatol 12 : 406-9.

10. Kim CK, Kim JJ, Chi SC, Shim CK (1993) Effect of fatty acids and urea on the penetration of ketoprofen through rat skin. International Journal of Pharmaceutics 99: 109-118.
11. Ongpipattanakul B, Burnette RR, Potts RO, Francoeur ML (1991) Evidence that oleic acid exists in a separate phase within stratum corneum lipids. Pharm Res 8: 350-354.

12. Fuhrman LC Jr, Michniak BB, Behlb CR, Malick AW (1997) Effect of nove penetration enhancers on the transdermal delivery of hydrocortisone: an in vitro species comparison Journal of Controlled Release 45: 199-206.

13. Hadgraft J, Peck J, Williams DG, Pugh WJ, Allan G (1993) Molecular modeling of skin permeation enhancement by chemical agents In: K.A. Walters and J. Hadgraft, Editors, Pharmaceutical Skin Penetration Enhancement. Marce Dekker: New York 389-416.

14. Godavarthy SS, Yerramsetty KM, Rachakonda VK, Neely BJ, Madihally SV (2009) Design of improved permeation enhancers for transdermal drug delivery. J Pharm Sci 98: 4085-4099.

15. Elshafeey AH, Sami El (2008) Preparation and in vivo pharmacokinetic study of a novel extended release compression coated tablets of fenoterol hydrobromide. AAPS PharmSciTech 9: 1016-1024. 